\title{
MASTEP
}

CrESI PRCES

PROGRESS REPORT

for the period

H. C. $3.00 ;$;

\section{DIFFUSION STUDIES IN LIQUID METALS}

United States Atomic Energy Commission Contract No, AT $(11-1)-841$

\section{Principal Investigator \\ R. A. Swalin}

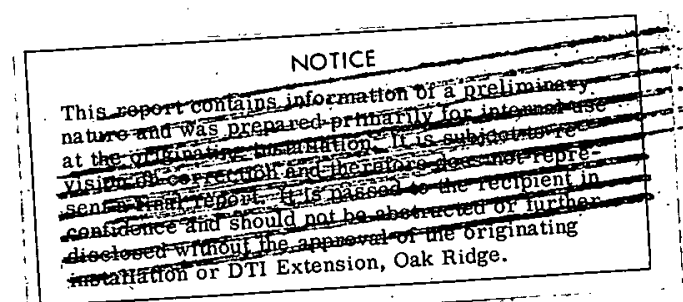<smiles>CCOCCOCCOCCOCCO</smiles>

School of Mineral and Metallurgical Engineering

University of Minnesota

Minneapolis,-Minnesota - 5545.5

May 15, 1967

\section{LEGAL NOTICE}

This report was prepared as an account of Government sponsored work. Neither the United States, tor the Commission, nor any person acting on behalf of the Commission:

A. Makes any warranty or representation, expressed or implied, with respect to the accuy. completeness, or usefuiness of the information contained in this report, or that the use privately owned rights: or . A ged rinto; or B. Assumes any liabllities with respect to the use of, or for damages resulting from the
use of any information, apparatus, method, or process disclosed in this report.

ployee or contractor of the "person acting on behalf of the Commission" includes any employee or contractor of the Commission, or employee of such contractor, to the extent that auch employee or contractor of the Commission, or employee of such contractor prepares, disseminates, or provides access to, any information pursuant to his employment or contract
with the Commission, or his 


\section{DISCLAIMER}

This report was prepared as an account of work sponsored by an agency of the United States Government. Neither the United States Government nor any agency Thereof, nor any of their employees, makes any warranty, express or implied, or assumes any legal liability or responsibility for the accuracy, completeness, or usefulness of any information, apparatus, product, or process disclosed, or represents that its use would not infringe privately owned rights. Reference herein to any specific commercial product, process, or service by trade name, trademark, manufacturer, or otherwise does not necessarily constitute or imply its endorsement, recommendation, or favoring by the United States Government or any agency thereof. The views and opinions of authors expressed herein do not necessarily state or reflect those of the United States Government or any agency thereof. 


\section{DISCLAIMER}

Portions of this document may be illegible in electronic image products. Images are produced from the best available original document. 
Table of Contents

I. BRIEF SUMMARY OF ACTIVITIES

Page

II. RESEARCH PROGRESS . 3

A. X-ray Diffraction Program 3

B. Electrical Resistance Measurements 9

C. Self-Diffusion in Liquid Sodium 12

D. Solute Diffusion in Liquid Silver 13 


\section{BRIEF SUMMARY OF ACTIVITIES}

One of the primary purposes of the research being performed on this contract is to obtain information concerning the mechanism of atomic motion in liquids and the relation of atomic transport to the liquid structure. One side of our program is concerned with an examination of the role of local density fluctuations. To achleve this end measurements as a function of temperature and pressure are being made of the radial distribution function, electrical resistivity and atomic diffusivity for liquid sodium. The other side of the program involves the study of solute diffusion in the monovalent solvent silver. With regard to the X-ray program, high pressure apparatus has been constructed and complete data have been collected of the scattered X-ray intensity as a function of angle for sodium. These data have been obtained as a function of temperature and pressure in order to yield constant volume data. The raw intensity data will next be processed so as to yield the radial distribution function. It appears from preliminary examination of the raw data that the radial distribution function is quite insensitive to pressure.

The electrical resistivity program for sodium has been completed. Precise data have been obtained for the constant volume condition between the melting point $\left(97.8^{\circ} \mathrm{C}\right)$ to $350^{\circ} \mathrm{C}$. The resistivity as a function of temperature at constant volume is linear under these conditions. In the last Progress Report we reported evidence of some curvature. Further data showed the curve to be linear. This is not true for the resistivity versus temperature plot at constant pressure on the other band where considerable curvature is found. Some results for mercury have also been obtained. 
Measurements for the self-diffusivity in liquid sodium have been made as a function of temperature at constant pressure. The range covered to date is the same as that covered by Nachtrieb. We are desirous next of going to higher temperatures and thence to the constant volume condition.

Further data have been collected for our solute diffusion program. During the past year, the diffusion of $\mathrm{Ru}, \mathrm{Fe}$, and $\mathrm{Co}$ in liquid sllver has been studied. The "apparent activation energies" for $\mathrm{Ru}$ and $\mathrm{Fe}$ are very large compared to that for the self-diffusion of silver in silver. Co on the other hand is much like Ag in its diffusion behavior. The data appear to be consistent with either the fluctuation model or hole theory of diffusion. Our earlier results for the homovalent solute $\mathrm{Au}$ and for elements to the right of $\mathrm{Ag}$ on the periodic table, namely, In, $\mathrm{Sn}$ and $\mathrm{Sb}$ were consistent with the expected valencies of these elements. The elements $\mathrm{Ru}, \mathrm{Fe}$ and Co studied this year are to the left of $\mathrm{Ag}$ on the periodic table and would superficially be expected to have valencies of $-3,-3$, and -2 respectively. The diffusion results are consistent with values of $-2,-1,5$, and -0.1 respectively. Thus the charge states of these solutes in the liquid state appear to be anomalous as is found to be the case for the solid state as well. 


\section{RESEARCH PROGRESS}

Work has proceeded along four interrelated avenues during the past contract year as described briefly in Section I. A more detalled account of the progress accomplished is discussed here.

\section{A. X-ray Diffraction Program}

Because of the importance of the X-ray interference function to scattering theory and hence to the electrical resistivity we have measured the diffuse scattering of $X$-rays by liquid sodium at constant volume from about $100^{\circ} \mathrm{C}$ to $200^{\circ} \mathrm{C}$. From this we hope to determine a sufficiently accurate $1(\mathrm{~s})$ as a function of temperature at constant volume. Subsitution of these data into the integral equation for the transport cross-section should give us the slope of the resistivity versus temperature curve and hence provide a rigorous test of the theory. An experimental report of the X-ray scattering work is given in the following pages. A description of the experimental apparatus employed was given in the last Progress Report $(\mathrm{COO}-841-8)$ and will not be repeated here: Rather attention will be focussed on results obtalned during the past contract year.

The diffraction pattern of liquid sodium, was measured at different temperatures between the melting point and $192^{\circ} \mathrm{C}$ for different pressures above, below and at constant volume. As introduction a short review is given on the mathematical evaluation of $g(r)$ the radial distribution function (RDF) from the measured diffracted intensity. The RDF is related to the incoherent scattered 
radiation by the equation

$$
4 \pi r^{2} \rho 0(g(r)-1)=2 r / \pi \cdot \int_{0}^{\infty} s .1(s) \cdot \sin s r d s
$$

with

$$
i(s)=\frac{I^{\operatorname{coh}} u_{i}}{N f^{2}}-1
$$

$S_{0}=$ bulk density of liquid sodium

$$
\begin{aligned}
& g(r)=R D F \\
& s=\frac{4 \pi \sin \theta}{-h}
\end{aligned}
$$

$f=$ corrected atomic scattering function of sodium

$I_{e_{i} u_{\bullet}}^{c o h}=I_{e u}^{E x}-I^{\text {Inc: }}$

$I_{\text {inc }}=$ incoherent scattered intensity of $\mathrm{Na}$

$I_{\text {eu }}^{E x}=$ normalized and corrected scattered intensity obtained by the experiment. subscript eu $=$ electron units

Introducing the normalization to electron units eq (2) becomes

$$
i(s)=\frac{C / N I_{s}^{E x} \operatorname{cor}(c p s)-\left(I_{\text {inc }}+f^{2}\right)}{f^{2}}
$$

$C=$ Normalization factor

subscript $\mathbf{s}=$ sample

cps = counts per second 
The following corrections are necessary to obtain $\mathrm{I}_{\mathrm{S}}^{\mathrm{Ex}}$ corr

Correction for the polarization of X-rays monochromatized on

a quartz single crystal, using Cuki radiation

$$
P=\frac{1-0.7985 \cos ^{2} 2 \theta}{1.7985}
$$

Absorption correction for absorption in the beryllium cylinder and sodium sample for a partially exposed sample and cell.

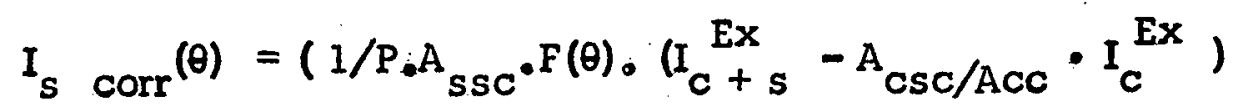

eq $(5)$ contains the polarization correction $P(\theta)$ and a correction $F(\theta)$ for the absorption of the incoherent scattered radiation.

$$
\begin{aligned}
& I_{c+s}=\text { measured intensity diffracted by sample and cell } \\
I_{c}^{E x}= & \text { measured intensity diffracted by the empty cell. } \\
A_{\text {SSC }}= & \text { absorption factor for absorption in sample and cell if } \\
& \text { scattering takes place in the sample } \\
A_{C S C}= & \text { absorption factor for absorption in sample and cell if scattering } \\
& \text { takes place in the cell } \\
A_{C C}= & \text { absorption factor for absorption in the cell if scattering takes place } \\
& \text { in the cell. }
\end{aligned}
$$

Kending and Pings ${ }^{1)}$ calculated the absorption factors for a partially exposed

1) Kending \& Pings, J. appl. Phys. 36 (1965) 1692 
cylindrical sample and cell. From these calculations a computer program was written by Kending ${ }^{2)}$, Fortran $\mathrm{N}$. The same program was used after conversion to Fortran II to calculate the three absorption factors as a function of scattering angle. The following components go into the calculation: dimension of sample and cell, radiation wavelength, mass absorption coefficients of aample and cell and the geometry of the intersecting X-ray beam. The absorption factors were calculated in steps of $\Delta \theta=2.5^{\circ}$ in the range between 2.5 and $72^{\circ}$. The intermediate values in steps of $\Delta \theta=0.25^{\circ}$ were obtained by an Aitken interpolation program from the original computed values. The $F(\theta)$ values were obtained in a similar manner from original values computed from the cell geometry in steps of $\Delta \theta=10^{\circ}$.

For the final measure serles 6 diffraction curves of the empty beryllium cylinder were obtained and 14 complete diffraction curves at seven different temperatures between $95^{\circ}$ and $192^{\circ} \mathrm{C}$ from sodium in the cell were obtained. Two additional diffraction curves were obtained at room temperature. To observe more closely the change of the first liquid peak with temperature and pressure, 36 partial diffraction curves between $2 \theta=20^{\circ}-45^{\circ}$ were investigated in addition. The locations on the P-T diagram, where the diffraction curves were taken, are shown in Fig. 1.

The diffraction curves from the chart-(Intensity as fct $(2 \theta)$ - were corrected against a standard in cps taken before and after each measurement.

2) Kending: Digital Computer Program for X-ray absorption factors for partially exposed annular sample cells. 1963 Calif: Inst. of Technol. Pasadena 
한

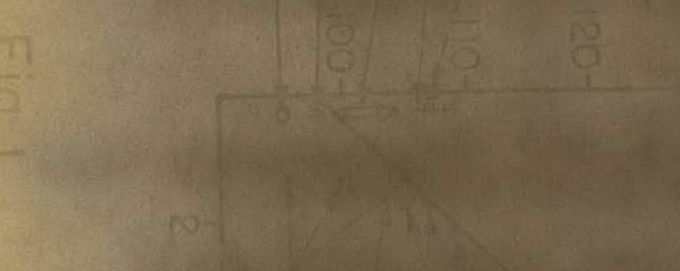

7)

$\frac{\frac{4}{3}}{\frac{3}{4}}$

$\frac{6}{\frac{6}{9}}$

Q

$\frac{0}{\frac{0}{2}}$

$\begin{array}{lll}0 & 0 & 10 \\ 5 & 0 & x \\ \frac{5}{2} & 5 & 0 \\ 0 & 1 & \frac{5}{2}\end{array} \mid$ 
The corrected intensities - cps as fct $(2 \theta)$ - were tabulated in steps of $\Delta(2 \theta)=0.5^{\circ}$.

The relation between the registered curves, taken with a speed of $2^{\circ}$ per minute, and a static curve obtained by setting the angle $2 \theta$ by hand and counting for $40 \mathrm{sec}$, were established in prellminary experiments. The curves proved to be identical, except that the reflection peaks of the beryllium show a lower maximum and were shifted about $0.1^{\circ}$ to higher values of $2 \theta$ for the recorded curves. This fact is unimportant for the results, however, because the Be-peaks are excluded from the measurements later on.

The most striking shift of the liquid sodium peak can be observed with temperature. Fig. 2 shows diffraction curves for 5 different temperatures around the melting point of $97.83^{\circ} \mathrm{C}$ at constant pressure. The peak intensity increases as the temperature is raised a few degrees above the melting point. How the iniensity changes with yet higher temperatures can be seen in Fig. 3 with $\mathrm{T}_{\text {melt }}$ at $104^{\circ}, 154^{\circ}$ and $191^{\circ} \mathrm{C}$ respectively for constant volume. It is obvious that the intensity decreases with higher temperature from $104^{\circ} \mathrm{C}$ on. The statistical scatter of the measure values can be seen best for the $104^{\circ} \mathrm{C}$ curve where 4 independently taken curves are plotted.

To demonstrate the relation between peak intensity and temperature, a series was taken with fixced peak angle $2 \theta=28.9^{\circ}$ and constant pressure as shown in Fig. 4. The intensity jump at the melting tempernture gives an intensity increase of about $40 \%$ foliowed by a monotonic decrease in intensity with temperature. 


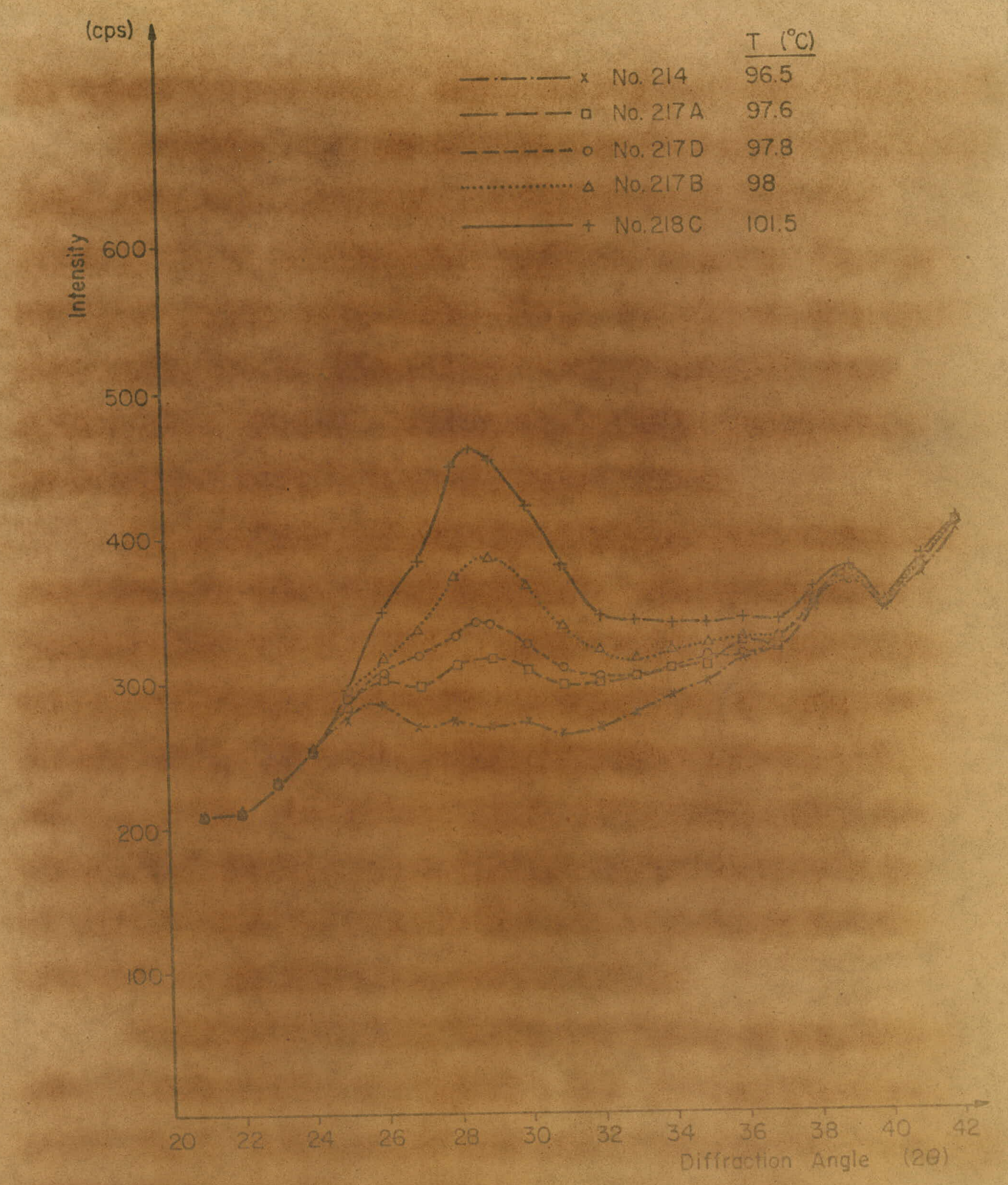

Fig.2 Liquid Sodium Peak below and above Melting Point at Constant Pressure $P=340$ psi 


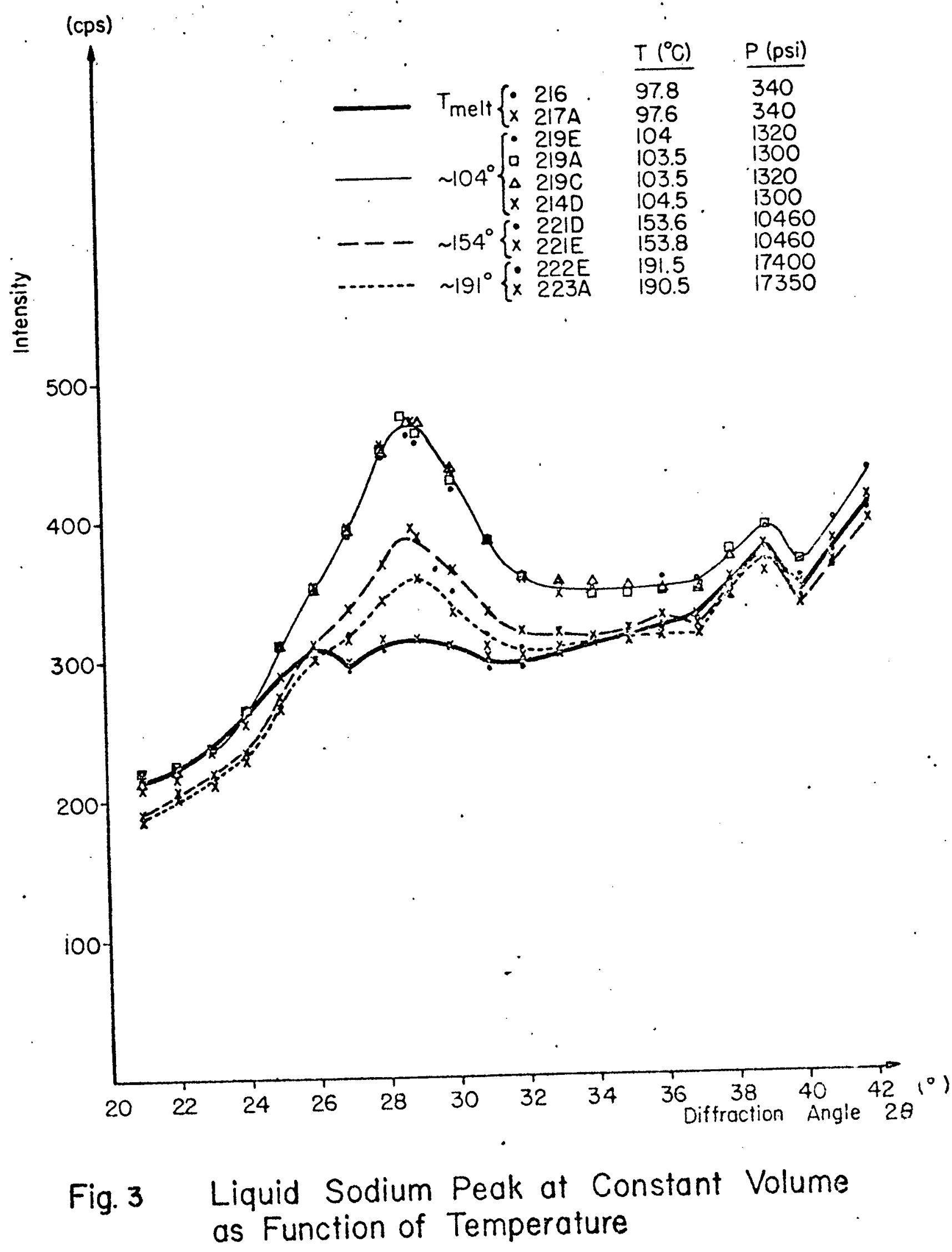




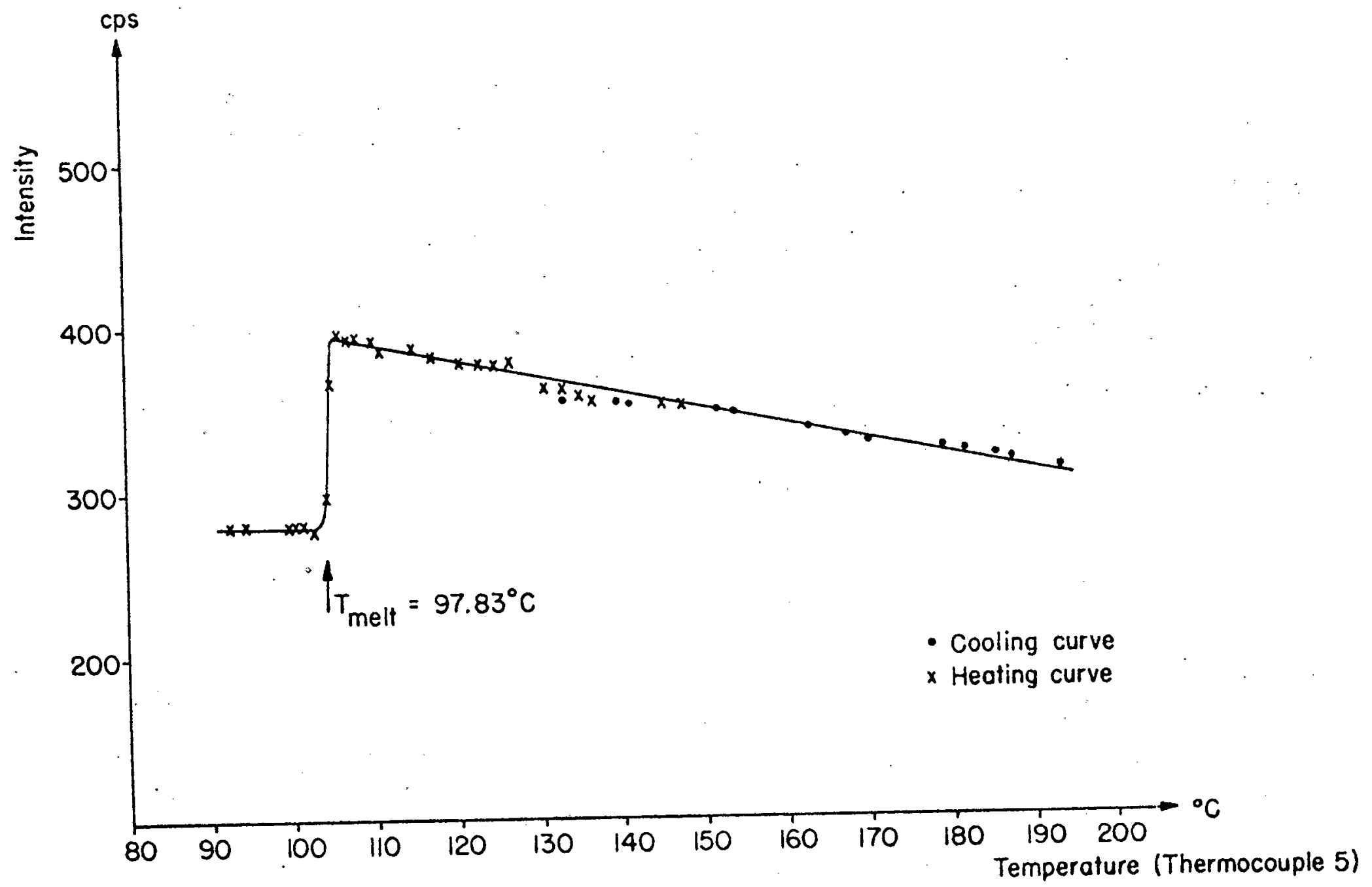

Fig. 4 Intensity (cps) as Function of Temperature at Constant Pressure of $320 \mathrm{psi}$ and $2 \theta=28.9^{\circ}$ 
Another set of measurements were made to show the effect of pressure on the liquid peak. At constant temperature several diffraction curves were taken under the constant volume condition described in Fig. $I$ and also some data were taken at different pressures. Fig, $5 \mathrm{a}$ and $\mathrm{b}$ show three curves for $103.5^{\circ} \mathrm{C}$ and two curves for $107^{\circ} \mathrm{C}$ under constant volume conditions and also for lower pressures as well. No clear pressure effect is detectable.

Fig. 6 shows similar data for a slightly higher temperature.: Fig: 6a shows the statistical scatter for three curves taken at a constant pressure of 330 psi. In Fig. $6 \mathrm{~b}$ the scattering range is marked by perpendicular lines, with repeated $D$ curve. The points meeting the constant volume condition at 2630 psi are shown and one curve with much higher pressure of $17830 \mathrm{psi}$ is also included. For the highest pressure a change of peak position to higher $2 \theta$ values and a slight decrease of intensity seems to be observable.

In Fig. 7 the liquid sodium peaks at constant volume and lower pressures are given for three higher temperatures. In Fig. 7c a slight shift of the peak with higher pressure can be observed in comparison to the 330 pst curve. Fig. 8 shows the intensity over the entire pressure range between 18000 psi and one atmosphere for constant angle $2 \theta=28.9^{\circ}$ and constant temperature of $188^{\circ} \mathrm{C}$. There is no intensity change with pressure between 18000 psi and about 300-400 psi. All measured points lie within the $90 \%$. confidence limit. The maximum scattering between 300 psi and 18000 psi was $\pm 1 \%$ Each point was counted for 100 seconds. 




a) Na.219

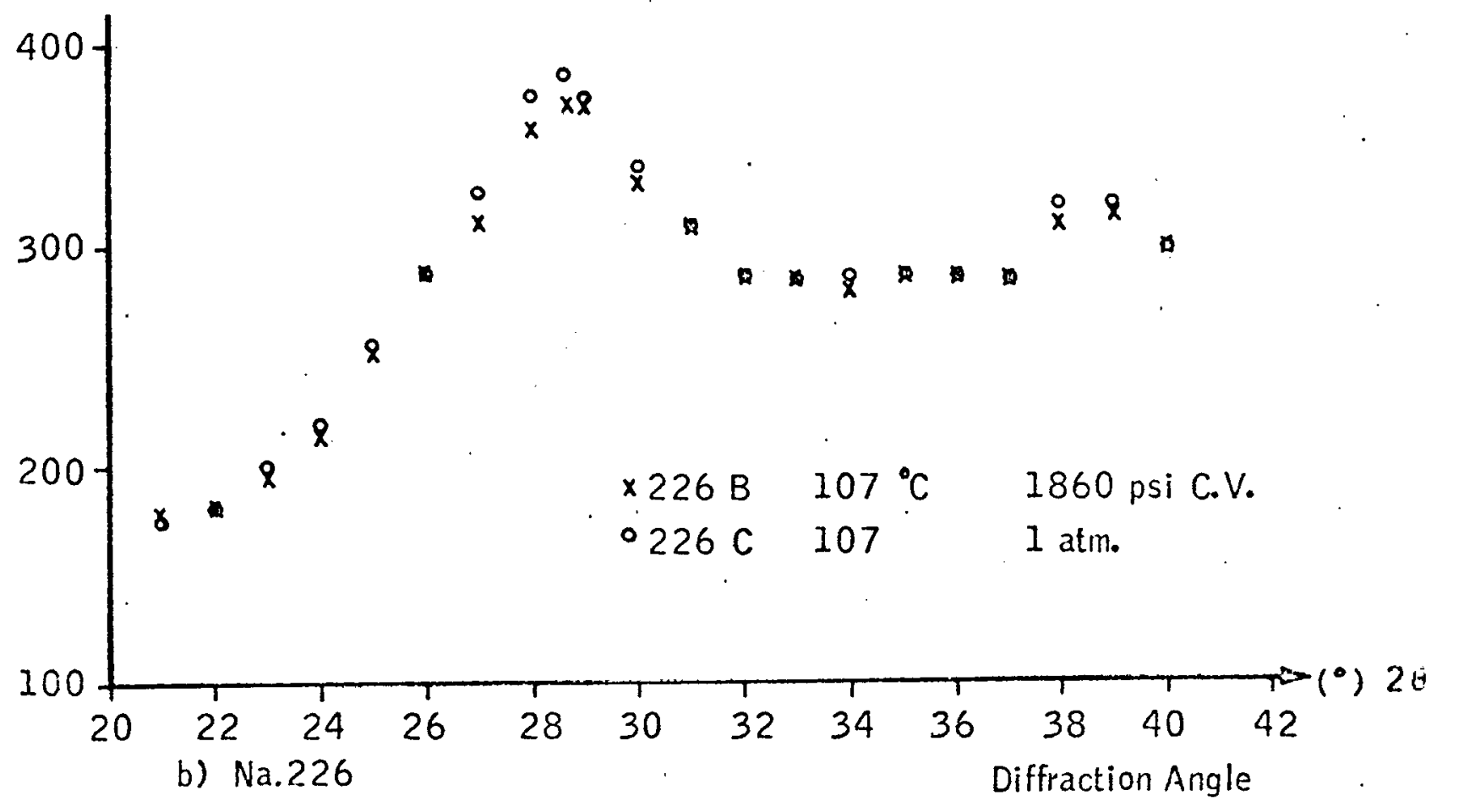

Fig.5 Liquid Sodium Peak at Constant Temperature With Pressure as Parometer. 

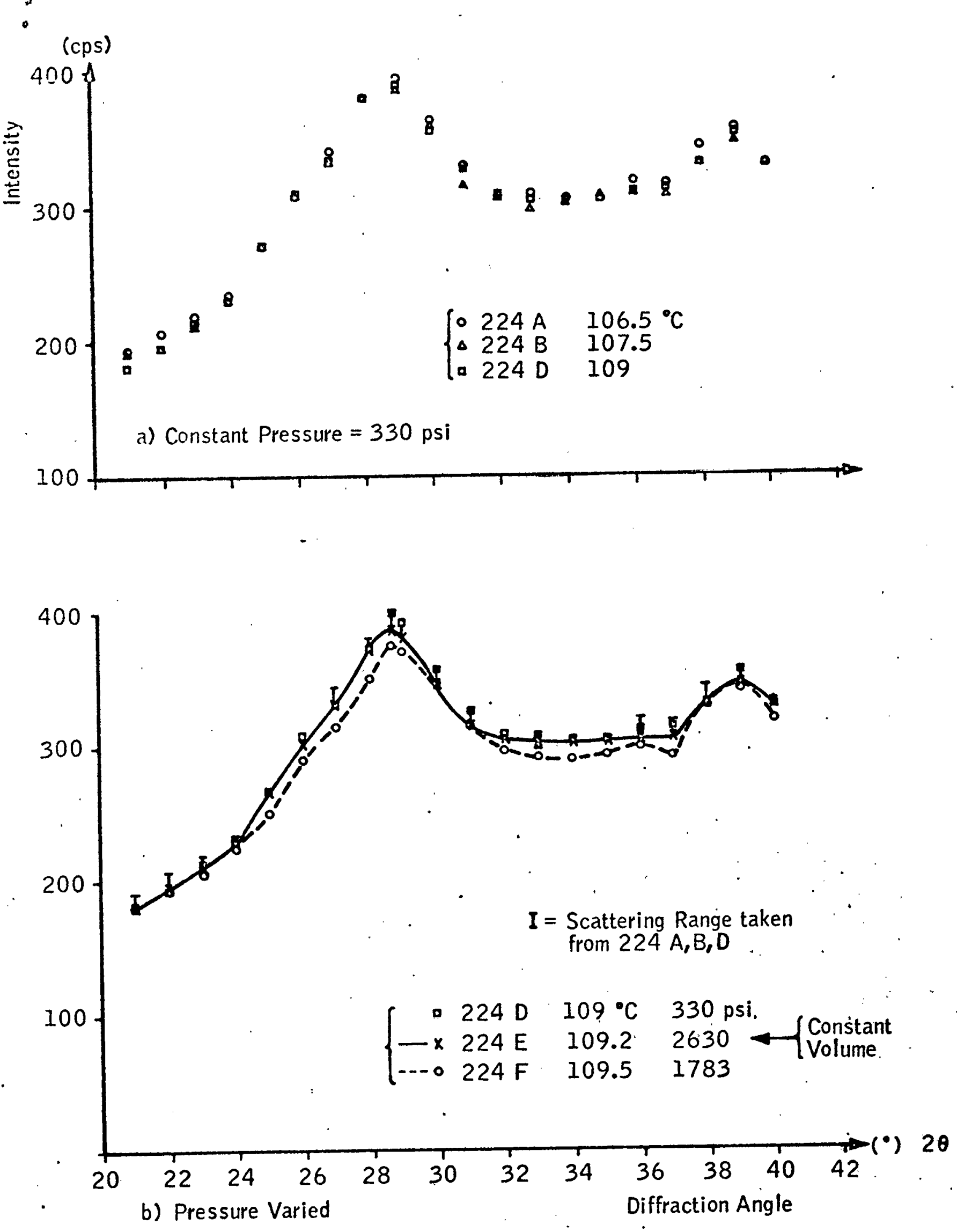

Fig. 6 No. 224 Liquid Sodium Peak at Constant Temperature at 3 Different Pressures. 


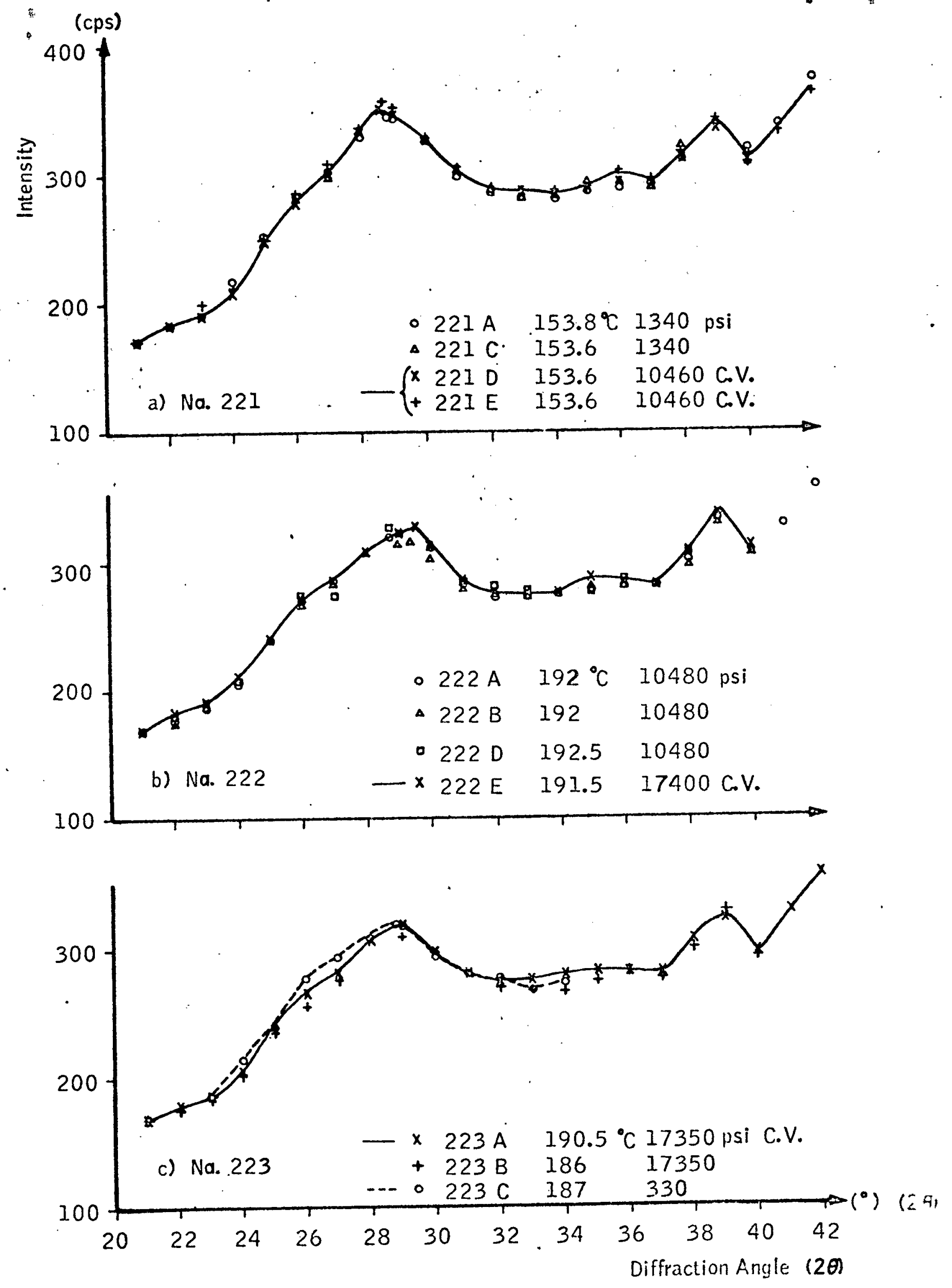

Fig. 7 Liquid Sodium Peak for Constant Temperature With Fresour? - Trenmelse. 


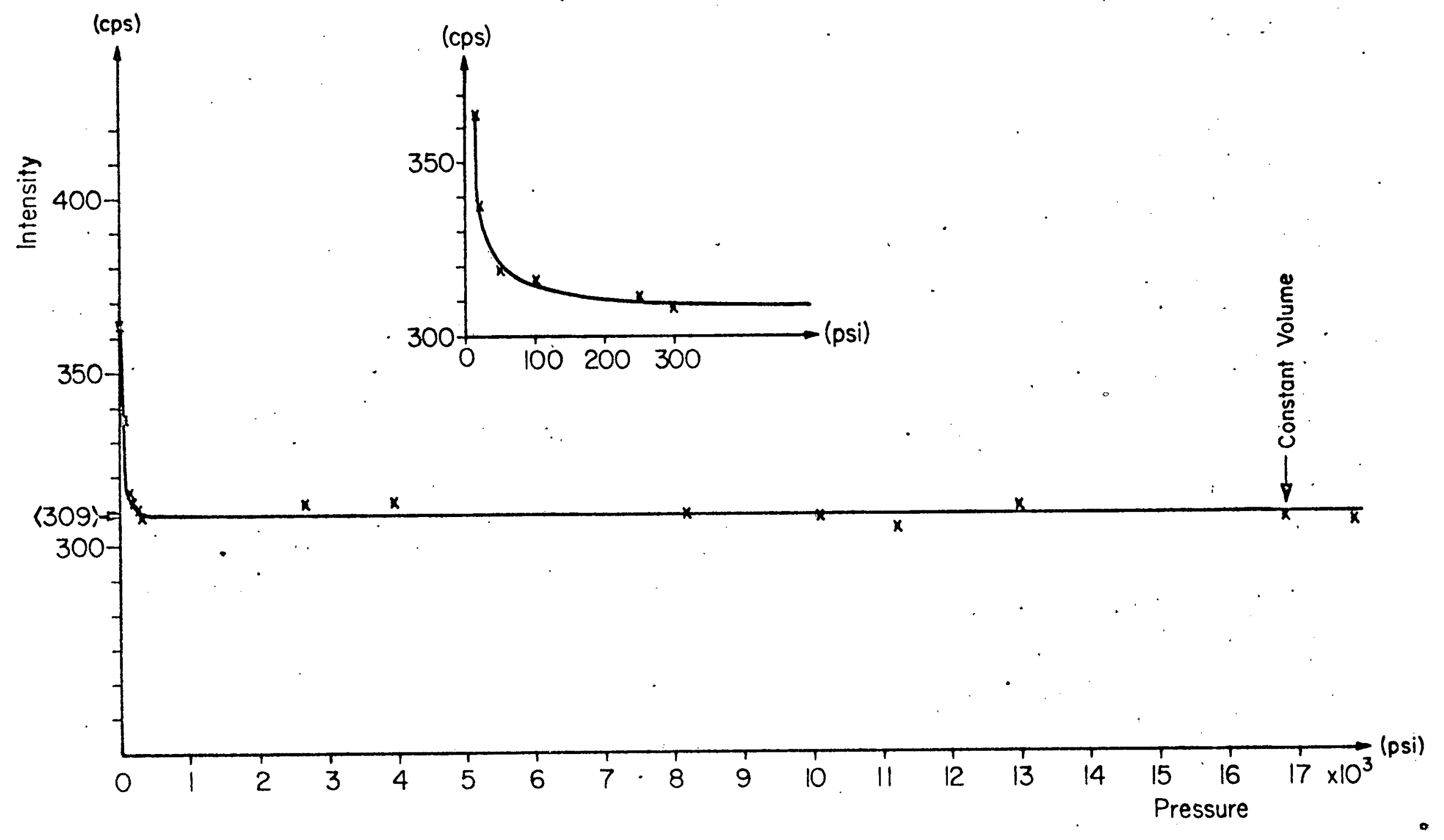

Fig. 8 Intensity (cps) as Function of Pressure at $T=188^{\circ} \mathrm{C}, 2 \theta=28.9^{\circ}$ 
At present, the corrected intensity $I_{s}$ corr is being computed from the precorrected intensity data shown above in order to use those values for the Fourier transform leading to the RDF as given in eq (1).

We would tentatively interpret our results as indicating that $1(s)$ and hence the $R D F$, is relatively insensitive to pressure: That is, temperature produces a much stronger effect on the RDF than pressure. It appears that this may be due to the relatively small ion-core size of sodium compared to Its atomic volume in the liquid.

\section{B. Electrical Resistance Mieasurements}

The electrical resistance measurements on sodium as a function of temperature have been completed for both the constant pressure and constant volume cases. The results are shown in the following curves along with a plot showing the P-T behavior of llquid sodium at constant volume from the melting point up to $350^{\circ} \mathrm{C}$. A complete discussion of the experimental approach is presented in earlier Progress Reports.

Most importantly, it should be noted in Fig. 9 that the resistivity at constant volume is linear with temperature from the melting_point all the way up to $350^{\circ} \mathrm{C}$. No apparent deviation from linearity is observed even at $350^{\circ} \mathrm{C}$. The relative temperature coefficient $\mathrm{T}_{\mathrm{m}}\left(\frac{\partial \rho}{\partial \mathrm{T}}\right) \mathrm{v}$ was found to be $7.743 \times 10^{-6} \Omega-\mathrm{cm}$. which is in good agreement with the value of $8.0 \times 10^{-6} \Omega-\mathrm{cm}$ measured by Endo for this same quantity (from $100^{\circ} \mathrm{C}$ to $170^{\circ} \mathrm{C}$ ). 


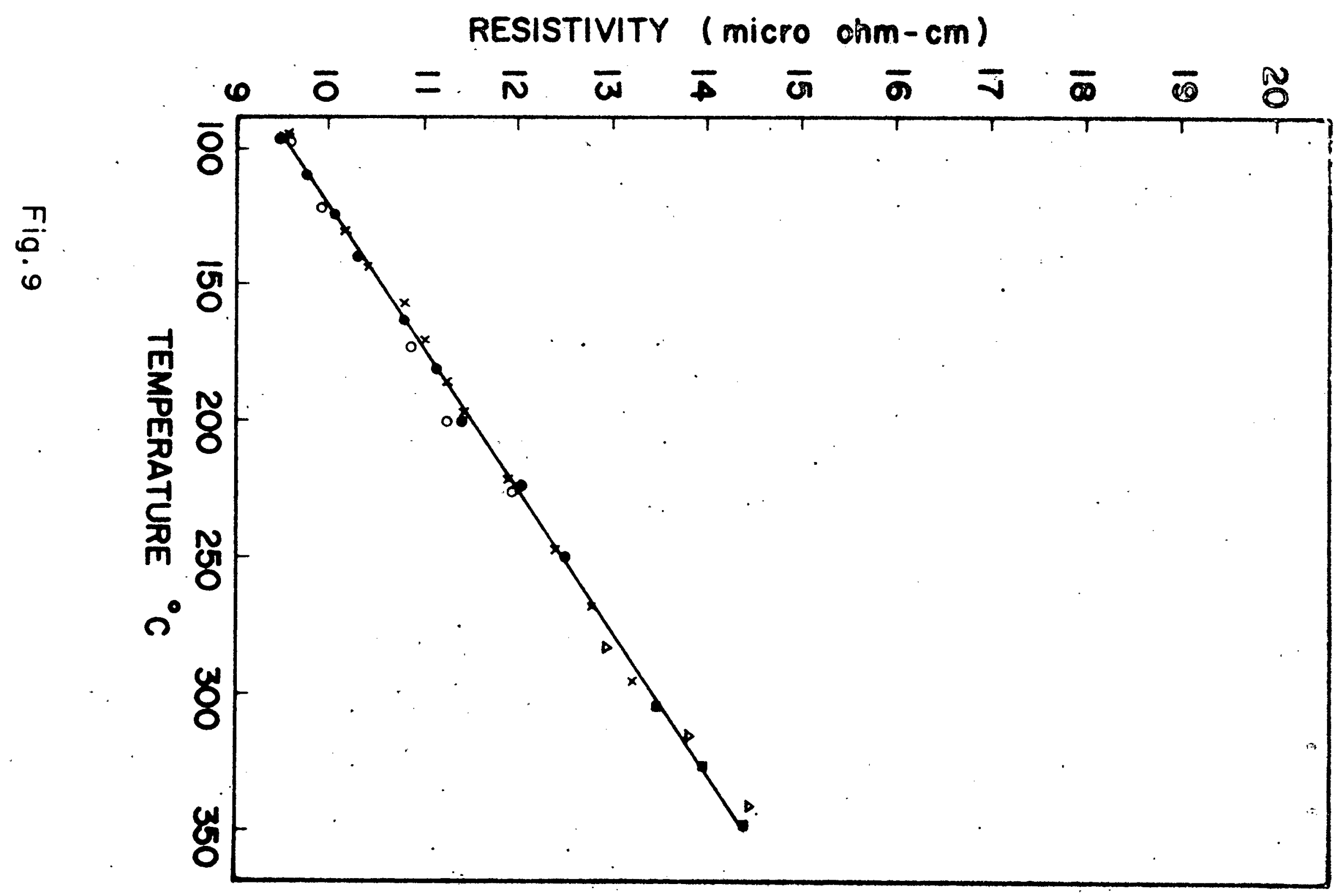


In Fig. 10 is represented the P-T constant volume behavior for sodium from $100^{\circ} \mathrm{C}$ up to $350^{\circ} \mathrm{C}$. The agreement between our results and Endo's is very good, being within about $2 \%$. The precision of our measurements is much better, however, as are the resistivity data.

In Fig. il the resistivity at constant pressure is shown to be linear with temperature up to almost $200^{\circ} \mathrm{C}$. The relative temperature coefficient over this range is a constant given as

$$
T_{m}\left(\frac{\partial \rho}{\partial T}\right)_{p}=12.7
$$

which is also in good agreement with Endo's result of 12.3 , measured for the temperature range from $100^{\circ} \mathrm{C}$ up to $170^{\circ} \mathrm{C}$. However, above $200^{\circ} \mathrm{C}$ there is a marked upward deviation of the constant pressure resistivity so that we should represent the resistivity by a parabolic curve of the form

$$
\rho=\rho_{0}+B(\Delta T)+C(\Delta T)^{2}
$$

Table 1. Experimental Coefficients of Resistivity vs. Temperature at Constant Pressure

Na:

$$
\begin{aligned}
\rho=\rho_{0}+B \Delta T+C(\Delta T)^{2} \\
\rho_{0}=9.505 \mu \Omega-\mathrm{cm} \\
B=3.306 \times 10^{-2} \mu \Omega-\mathrm{cm} /{ }^{\circ} \mathrm{C} \\
\mathrm{C}=2.144 \times 10^{-5} \mu \Omega-\mathrm{cm} /{ }^{\circ} \mathrm{C}^{2}
\end{aligned}
$$

from MP. $\left(97.8^{\circ} \mathrm{C}\right)$ to $350^{\circ} \mathrm{C}$

Hg:

$$
\begin{aligned}
\rho=\rho_{0} & \text { B } \Delta T+C(\Delta T)^{2} \\
\rho_{0} & =91.23 \mu \Omega-\mathrm{cm} \\
B & =7.749 \times 10^{-2} \mu \Omega-\mathrm{cm} /{ }^{\circ} \mathrm{C} \\
\mathrm{C} & =9.037 \times 10^{-5} \mu \Omega-\mathrm{cm} /{ }^{\circ} \mathrm{C}^{2}
\end{aligned}
$$

from $\mathrm{Mp}\left(-38.4^{\circ}\right)$ to $260^{\circ} \mathrm{C}$ 


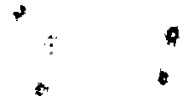

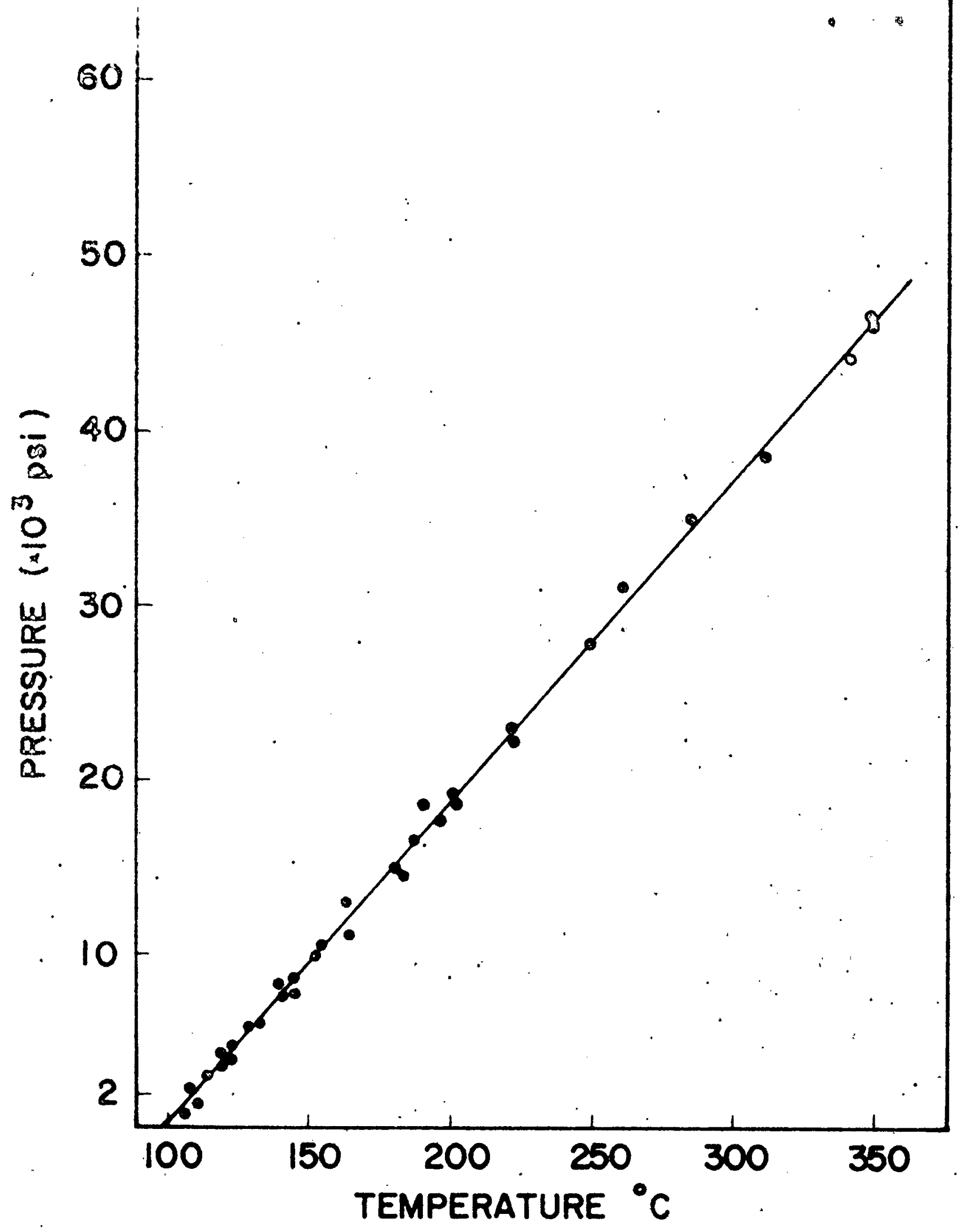

Fig. 10 


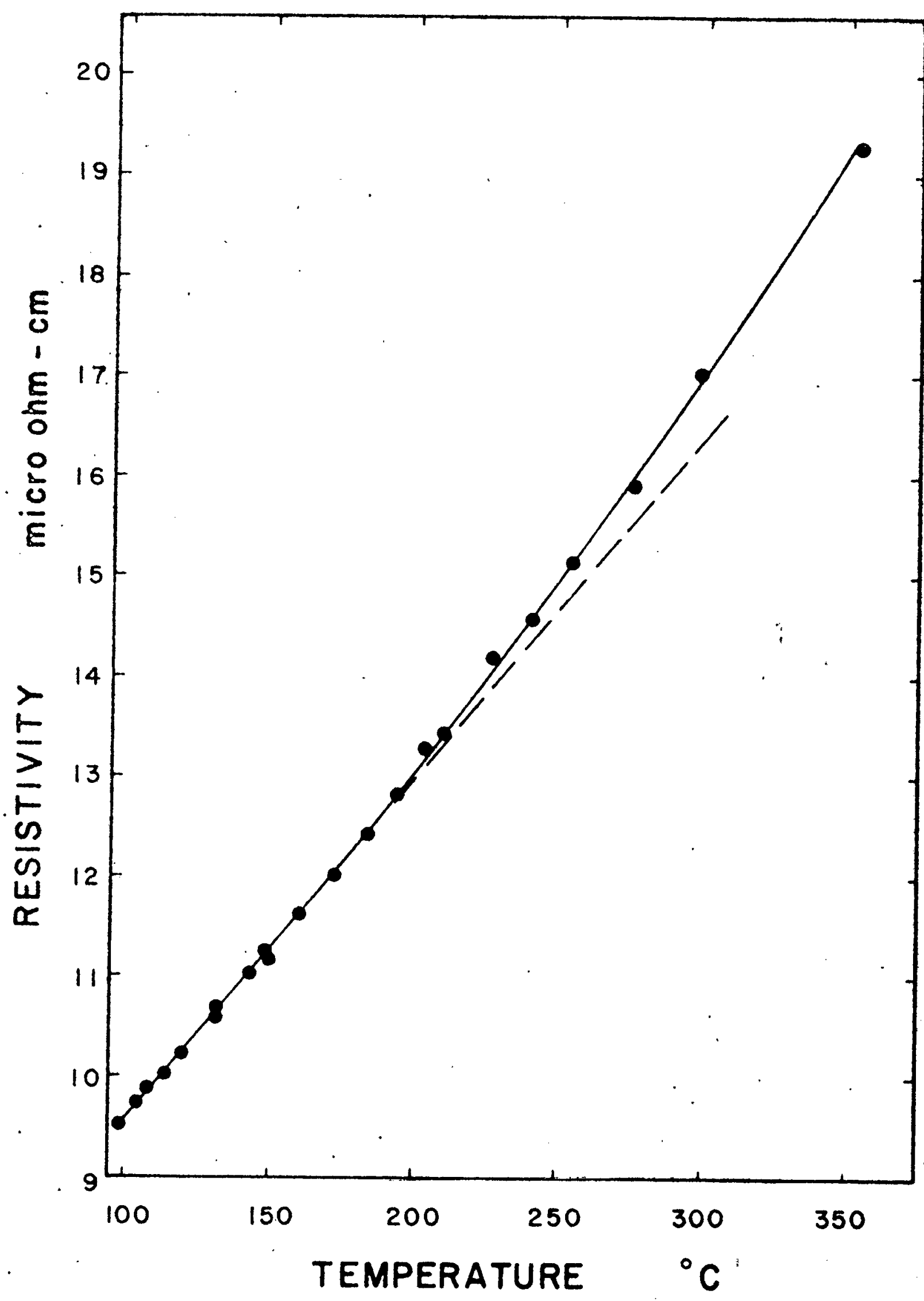

Fig.11. Resistivity of pure liquid sodium at constant pressure (I atm.) 
$\rho_{0}=$ the resistivity at the melting point and $\Delta T=\left(T-T_{m}\right)$, the temperature increment relative to the melting point. Over the whole temperature range of our measurements there is quite good agreement with the results of Freedman and Robertson for resistivity at constant pressure. Measurements made on mercury were also made at constant pressure and constant volume. The results at constant pressure are shown in Fig. 12. The results shov reasonably good agreement with data reported for these two cases.

The primary result of interest is that we have measured the resistivity at constant volume at least $180^{\circ} \mathrm{C}$ higher than anyone else and that it is still definitely linear with temperature. Theoretically, this is the result predicted by Ziman and by Sivertsen. The results of both are formally identical but are based on essentially different physical hypotheses. ZIman assumes a temperatureindependent structure term plus a temperature dependent plasma term. Sivertsen's result is essentially an extension of the method of deformation potentials where the potential fluctuations producing the scattering arise from the density fluctuations in the liquid which are linearly temperature dependent. In any case, a linear temperature dependence implies small energy gaps with the resulting scattering dominated by small angle scattering. A small energy gap is consistent with the known properties of sodium and hence our result is consistent with other properties of sod ium. 


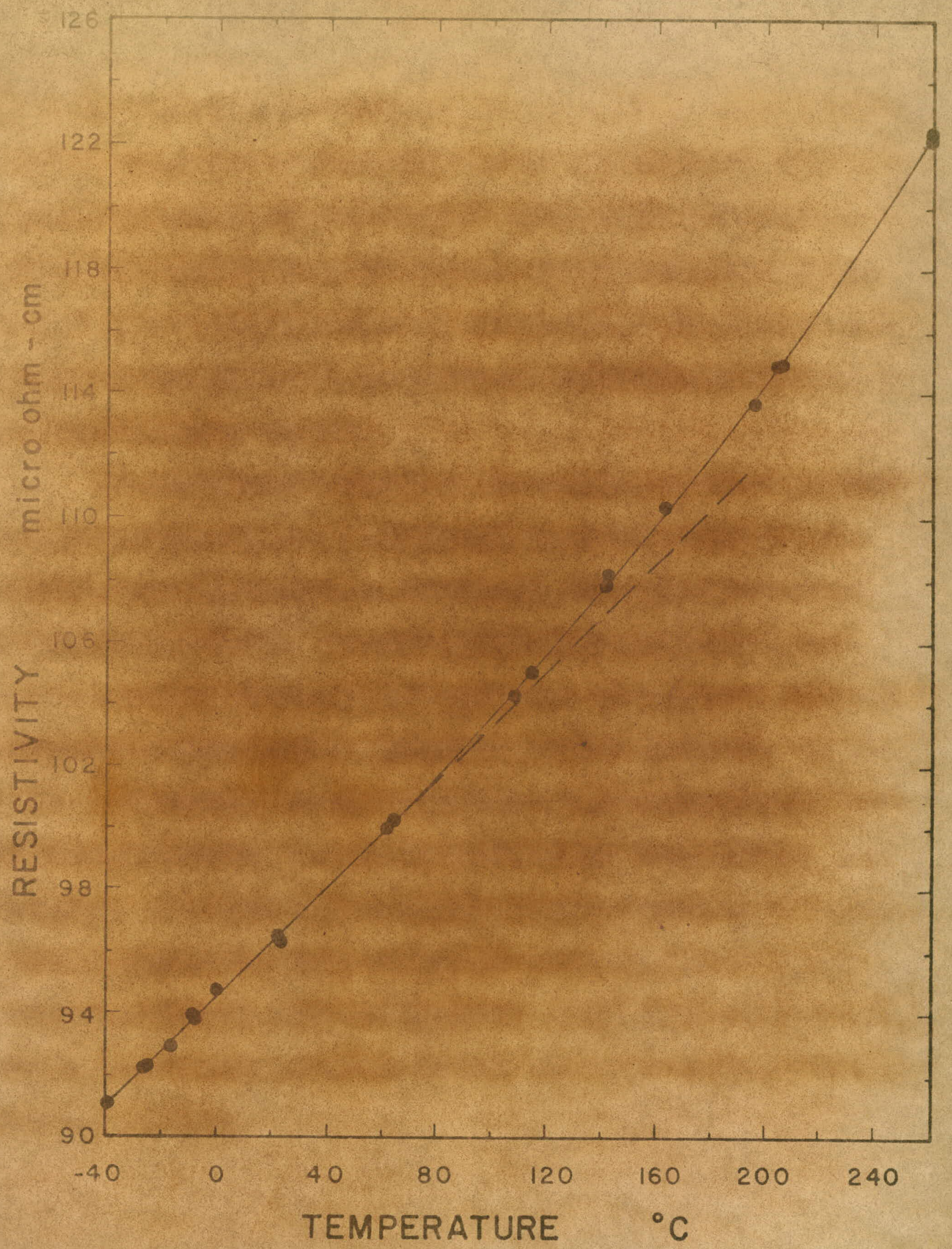

Fig. 12 Resistivity of pure liquid mercury at 
C. Self-Diffusion in Liquid Sodium

As mentioned in previous reports, it is desirable to know the diffusivity in liquild sodium as a function of temperature under conditions of constant volumes In order to compare experiment with the prediction of various theories.

There are several theoretical models for the diffusion of atoms in liquids, each predicting a different dependence of $D$ upon temperature. To date, experimental results have not been sufficiently accurate to discriminate between these models. In order to do this, a large temperature range must be investigated since it is at elevated temperatures that the differences between theoretical predictions become more pronounced. In the case of $\mathrm{Na}$ (melting point, $97^{\circ} \mathrm{C}$ ) It is hoped to determine $\mathrm{D}$ values up to temperatures in the region of $500^{\circ} \mathrm{C}$. The experimental technique, described in detall in the last Progress Report (COO-841-8), comprises a caplllary, one half of which is filled with $\mathrm{Na}$ which contains radioactive isotope $\mathrm{Na}^{22}$. The other half contains non-radioactive Na. Diffusion takes place across the interface between the two halves. The analysis for determining the distribution of $\mathrm{Na}^{22}$ is carried out by means of the sectioning technique and a scintillation counter.

The silicone oil-bath at present being used to perform the diffusion anneal experiments at constant pressure can be used only at temperatures below $200^{\circ} \mathrm{C}$. It is proposed, therefore, to construct a suitable furnace in order to extend the temperature range to the desired $500^{\circ} \mathrm{C}$. Diffusion anneals will then be carried out in an argon atmosphere. 
Results to date are presented in Fig. 13 plotting $D$ as a function of the absolute temperature. The previous results of Ivata from this laboratory and Meyer and Nachtrieb ${ }^{(3)}$ are included for comparison. Agreement is reasonable. It must be emphasized that the present results constitute a preliminary survey in order to establish the correct experimental procedure: Future investigations will be more thorough, undertaking several diffusion anneals at each given temperature. This will allow a study of the effect of diffusion time upon the calculated $\mathrm{D}$ value with a view to examining for errors due to thermal convective stirring. Such inaccuracies should be minimal so long as the length to diameter ratio of the capillary is large. In the present work this ratio is 100.

Preparations for commencing the self-diffusion program at constant volume are underway. Apparatus already in extstence is to be used for this purpose, with slight modifications to the pressure vessel and furnace.

It was anticipated in last year's proposal that this program would be further along and perhaps nearing completion by this time. Dr. Iwata who performed the earlier research in our laboratoy was obligated to terminate the research prematurely in 1966, however, and the work was not plcked up again until January, 1967.

\section{Solute Diffusion in Liquid Silver}

Since the last Progress Report, a study of diffusion of electronegative solutes, $\mathrm{Ru} ; \mathrm{Fe}, \mathrm{Co}$ in liquid silver has been completed. The experimental (3) R, E. Meyer and N. Nachtrieb, J.0.Chem. Phys, 23, 1851 (1955). 




(c)

\%

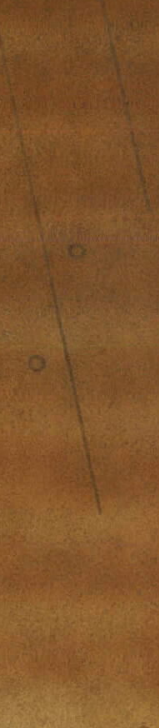


results can be conveniently expressed as:

$$
\begin{aligned}
D_{\text {Ru-Ag }}= & (2.24 \pm 0.56) \times 10^{-3} \exp \left[-\frac{11,250 \pm 720}{R T}\right] \\
D_{\text {Fe-Ag }}= & (1.16 \pm 0.21) \times 10^{-3} \exp \left[-\frac{9.560 \pm 510}{R T}\right] \\
D_{\text {Co-Ag }}= & (5.81 \pm 1.83) \times 10^{-4} \exp \left[-\frac{7.830 \pm 620}{R T}\right]
\end{aligned}
$$

From the experimental results, it is evident that $\mathrm{Ru}$ and Fe diffuse with an apparent higher activation energy than that for self-diffusion in liquid sllver, while Co diffusion has nearly the same temperature dependence as self-diffusion in liquid sllver (apparent activation energy $7,660 \pm 720 \mathrm{cal} / \mathrm{g}$.mole).

The basic aspects of the experimental techniques have been described in earlier reports. For the case of $\mathrm{Ru}, \mathrm{Fe}, \mathrm{Co}$, the technique had to be modified in several ways: (i) the electrodepositton of these elements on liquid silver had to be carried out under strict control of the $\mathrm{pH}$ of the electrolyte; (ii) the $\mathrm{pH}$ had to be changed for each element; (iii) after electrodeposition the deposited film vas always contained under purified inert atmosphere to prevent any surface oxidation; (iv) a high specific activity of the radioisotope was used to obtain only very small total amounts of the $\mathrm{Ru}, \mathrm{Fe}$, Co deposited because these elements have extremely limited solubility both in liquid and solid silver; (v) preparation of the radioactive silver bath was carried out in vacuum; (vi) Finally, several captllary samples withdrawn from the radioactive reservoir were checked to eliminate the possibility of any segregation and redistribution of the solute. 
The experimental data on diffusion of $\mathrm{Ru}, \mathrm{Fe}, \mathrm{Co}$ in Ag are consistent with the fluctuation theories and 'hole' theories of liquid diffusion, if the solute perturbation in the interionic potential is evaluated from the Thomas-Fermi approximation for the potential of a screened charge."

Calculations of the relative solute diffusivity in liquid silver and its temperature dependence have been also made in terms of the self-consistent Hartree treatment of the potential of a screened charge. The agreement between experiment and theory is thereby improved.

For better agreement between theory and experiment, however, it has been necessary to assign the following charges to solutes: for $\mathrm{Ru}=-2$, for $F e=-1.5$, and for $C o=-0.1$ instead of $-3,-3$, and -2 respectively as indicated by the Perlodic Table of Elements. The assigned charges are consistent with the avallable information on the magnetic properties of $\mathrm{Ru}, \mathrm{Fe}$ and $\mathrm{Co}$ alloys with silver and copper.

A paper glving the detalls of the results for the diffusion of $\mathrm{Ru}, \mathrm{Fe}$, and Co in liquid silver is being prepared by Y. P. Gupta. Preprints will be distributed as a Technical Report.

A paper on solute diffusion in liquid metals was presented by Y.P.Gupta at the International conference on Properties of Liquid Metals held at the Brookhaven National Laboratory during September 19-23, 1966. Preprints of this paper were sent to the U.S.A.E.C. as document COO-841-9. This paper is due to be published in May, 1967 in the Proceedings of the International Conference on Properties of Liquid Metals. 


\section{FIGURE CAPTIONS}

Fig. 1 PT-Diagram Showing Locations of Diffraction Curves

Fig. 2 Liquid Sodium Peak Below and Above Melting Point at Constant Pressure $P=340$ psi

Fig. 3 Liquid Sodjum Peak at Constant Volume as Function of Temperature

Fig. 4 Intensity (cps) as Function of Temperature at Constant Pressure of $320 \mathrm{psi}$ and $2 \theta=28.9^{\circ}$

Fig. 5 Liquid Sodium Peak at Constant Temperature With Pressure as Parameter

Fig. 6 No. 224 Liquidd Sodium Peak at Constant Temperature at 3 Different Pressures

Fig. 7 Liquid Sodium Peak for Constant Temperature With Pressure as Parameter

Fig. 8 Intensity (cps) as Function of Pressure at $\mathrm{T}=188^{\circ} \mathrm{C}, 2 \theta=28.9^{\circ}$

Fig. 9 Resistivity of Liquid Sodium as a Function of Temperature at Constant Volume

Fig. 10 Pressure versus Temperature Curve for Sodlum at Constant. Volume

Fig. 11 Resistivity of Pure Liquid Sodium at Constant Pressure (l atm.)

Fig. 12 Resistivity of Pure Liquid Mercury at-Constant Pressure (1 atmo)

Fig. 13 Diffusivity in Liquid Sodium as a Function of Temperature 